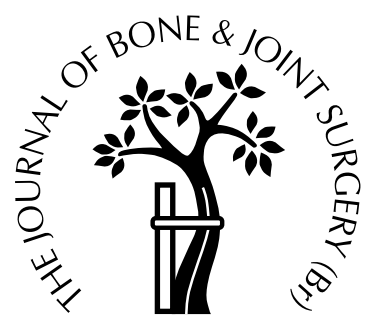

\title{
The influence of avascularity on the mechanical properties of human bone-patellar-tendon-bone grafts
}

\author{
Stefan Rupp, Romain Seil, Dieter Kohn, Bernd Müller \\ From the University of Saarland, Homburg/Saar, Germany
}

O ur aim was to analyse the effect of avascularity on the morphology and mechanical properties (tensile strength, viscoelasticity) of human bone-patellar-tendon-bone (BPTB) grafts in vitro. These were harvested at postmortem and stored submerged in denaturated human plasma at a constant $\mathrm{pH}, \mathrm{pO}_{2}, \mathrm{pCO}_{2}$, temperature and humidity under sterile conditions. Mechanical testing was performed two and four weeks after removal of the graft. The mean ultimate strength was $1085.7 \pm$ $255.8 \mathrm{~N}$ (control), 1009.0 $\pm 314.9 \mathrm{~N}$ (two weeks

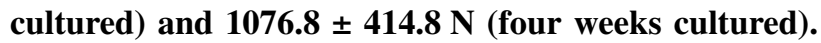
There was no significant difference in linear stiffness or deformation to failure between the groups. There was a difference in viscoelasticity between the control group and the avascular grafts and the latter had significant lower peak load-to-load ratios after 15 minutes compared with the control group. After two and four weeks the graft contained viable fibroblasts. There was regular cellularity in the superficial layers and decreased cellularity in the midportion. The structure of the collagen including the crimp pattern appeared to be normal in polarised light.

We conclude that avascularity does not significantly affect ultimate failure loads or stiffness of BPTB grafts. Slight changes in viscoelasticity were induced, but the significance of the increased stress relaxation is not fully understood.

J Bone Joint Surg [Br] 2000;82-B:1059-64. Received 24 May 1999; Accepted after revision 2 July 1999

S. Rupp, MD, Orthopaedic Surgeon, Associate Professor

R. Seil, MD, Orthopaedic Surgeon

D. Kohn, MD, Orthopaedic Surgeon, Professor

B. Müller, MD, Orthopaedic Surgeon

Department of Orthopaedic Surgery, University of Saarland, D-66421

Homburg/Saar, Germany.

Correspondence should be sent to Dr S. Rupp.

(C)2000 British Editorial Society of Bone and Joint Surgery 0301-620X/00/710222\$2.00

VOL. 82-B, No. 7, SEPTEMBER 2000
A bone-patellar-tendon-bone (BPTB) autograft is presently the most widely used graft for reconstruction of the anterior cruciate ligament (ACL). ${ }^{1}$ The advantages are the high tensile strength at the time of surgery and secure bone-tobone fixation.

The natural history of BPTB autografts has been well documented in animal experiments ${ }^{2-12}$ and in biopsy studies in man ${ }^{13-15}$ using histological and microvascular techniques. The transplanted patellar tendon undergoes changes in microstructure and structural properties. Four stages of autograft transformation have evolved: avascular necrosis, revascularisation, cellular proliferation, and remodelling. ${ }^{16}$ Some investigators have focused on the later stages analysing revascularisation, cellular proliferation, and remodelling. ${ }^{4,13,14}$ In accelerated rehabilitation after reconstruction of the $\mathrm{ACL}^{17}$ the behaviour of the graft in the immediate postoperative period is of more significance.

The graft is transplanted without a blood supply and therefore avascularity may be one of the major determinants of its environment within the first weeks after surgery. In animal models the graft tissue remains avascular for different periods of time. Revitalisation begins at two weeks in the rabbit ${ }^{8}$ and four weeks in the $\operatorname{dog}^{5}$ with round to ovoid cells visible at the margins of the graft $^{8}$ and a synovial membrane rich in vessels surrounding it. ${ }^{5}$ In the rabbit the number of cells within the graft dramatically increases at four weeks. ${ }^{8}$ In the dog intrinsic vessels are seen in the graft at eight weeks.

Data from animal experiments suggest a dramatic decrease in tensile strength after surgery, 6,9-11 reflecting the development of avascular necrosis. In these studies, however, the tibia and femur were both fixed to the testing machine thus evaluating both the graft and its graft fixation. When tested in the first weeks after surgery these constructs failed at the site of fixation, representing the weakness of fixation rather than the structural properties of the graft tissue. These studies are based on animal experiments and focus on ultimate failure loads. The viscoelasticity of the grafts, which may be as important for graft function as strength, was not examined.

We have therefore analysed the effect of avascularity on the morphology and mechanical properties, such as the tensile strength and viscoelasticity, of human BPTB grafts in vitro. 


\section{Materials and Methods}

We used a tissue-culture model to study avascularity in vitro and the experiments were performed in two series.

\section{Series 1}

The objective was to study ultimate failure loads and mode of failure of avascular grafts under high rates of strain and to assess the histological appearance after two and four weeks of tissue culture.

Specimens. Human BPTB specimens were obtained at postmortem within 24 hours of death from 11 pairs of knees. There were nine male and two female donors with a mean age of 57 years (42 to 69). We harvested two grafts from each patellar tendon, under sterile conditions, one each from the central and medial thirds, $10 \mathrm{~mm}$ in width with bone plugs from the patella and tibia. They were immediately placed in Petri dishes filled with physiological saline.

The grafts of one knee were assigned randomly to one of two tissue culture groups. Those of the opposite knee of each donor were used as a paired control and were tested immediately.

Tissue culture. The specimens were cultured in Petri dishes submerged in human plasma for two or four weeks. The plasma had been denaturated previously by increasing the temperature to $56^{\circ} \mathrm{C}$ for 20 minutes. An antibiotic for cell culture (penicillin/streptomycin, 3\%) was added to avoid bacterial infection.

The specimens were incubated at $37^{\circ} \mathrm{C}$ in a humidified atmosphere of $5 \% \quad \mathrm{CO}_{2} / 95 \%$ air (cell culture incubator; Nunc Inc, Wiesbaden, Germany). They were checked twice a week for bacterial growth and for the $\mathrm{pH}$ of the plasma which was changed each week.

Mechanical testing. We used a universal testing machine (type 1474; Zwick Inc, Ulm, Germany) to examine the tensile properties of the BPTB grafts at room temperature. Specimens were kept moist with saline solution. Both ends were attached to the machine by custom-made clamps. Each specimen was preconditioned cyclically (10 cycles between $40 \mathrm{~N}$ and $100 \mathrm{~N}$ ) and then allowed 15 minutes of recovery. It was were then loaded to failure at a rate of displacement of $500 \mathrm{~mm} / \mathrm{min}$. Load-deformation curves were registered for each test. From each curve we calculated the maximum load, linear stiffness and deformation to maximum load. The deformation was measured from clamp to clamp. The cross-sectional area was measured using calliper gauges. Maximum stress and elastic modulus were calculated.

Statistical analysis was performed using the Wilcoxon test for paired data.

Failure mode. There were four modes of failure: ligamentous disruption, avulsion of the tendon from the bone plug, fracture of the bone plug and complex failure with a longitudinal separation of tendon tissue and avulsion from the opposite bone plugs.

Statistical analysis was performed using the chi-squared test.

Histological analysis. Specimens were prepared after testing and stained with haematoxylin and eosin and MassonGoldner. They were analysed for cell viability and collagen structure (polarised light).

\section{Series 2}

The objective was to examine ultimate failure loads and failure modes of avascular grafts under low rates of strain and to assess viscoelasticity after two weeks of tissue culture.

Specimens. BPTB specimens were obtained at postmortem within 24 hours of death from eight pairs of knees. There were six male and two female donors with a mean age of 59 years (40 to 68). We harvested two tendon grafts from each patellar tendon under sterile conditions, one each from the central and medial thirds, $10 \mathrm{~mm}$ in width with bone plugs from the patella and tibia. They were immediately placed in Petri dishes filled with physiological saline.

The grafts of one knee were assigned to the tissueculture group and those of the opposite side were used as a paired control and were tested immediately.

Tissue culture. The specimens were cultured in Petri dishes submerged in human plasma for two weeks as described for series 1 .

Mechanical testing. We used the universal testing machine and procedure as described for series 1. Specimens were subjected to a static relaxation test. A strain inducing a graft load of $100 \mathrm{~N}$ was applied and maintained for 15 minutes. The percentage of peak load maintained was assessed every minute. The final load-to-peak-load ratios were calculated. The grafts were then returned to their resting lengths for 15 minutes of recovery.

The specimens were also subjected to a cyclic creep test. They were loaded for ten cycles between $40 \mathrm{~N}$ and $120 \mathrm{~N}$.

Table I. Series 1. Structural and material properties (mean \pm SD) of human BPTB grafts. The cross-head speed was $500 \mathrm{~mm} / \mathrm{min}$

\begin{tabular}{lccc}
\hline & & \multicolumn{2}{c}{ Avascular group } \\
\cline { 3 - 4 } & Control group & 2 weeks & 4 weeks \\
\hline Ultimate load $(\mathrm{N})$ & $1085.7 \pm 255.8$ & $1009.0 \pm 314.9$ & $1076.8 \pm 414.8$ \\
Linear stiffness $(\mathrm{N} / \mathrm{mm})$ & $118.5 \pm 30.8$ & $110.9 \pm 55.1$ & $113.5 \pm 40.7$ \\
Relative strain $(\%)$ & $25.7 \pm 5.6$ & $24.4 \pm 4.8$ & $24.5 \pm 4.7$ \\
Ultimate stress (MPa) & $33.9 \pm 7.3$ & $31.7 \pm 9.6$ & $32.8 \pm 12.0$ \\
Elastic modulus $(\mathrm{MPa})$ & $186.2 \pm 44.7$ & $185.6 \pm 64.1$ & $173.3 \pm 1.7$ \\
\hline
\end{tabular}




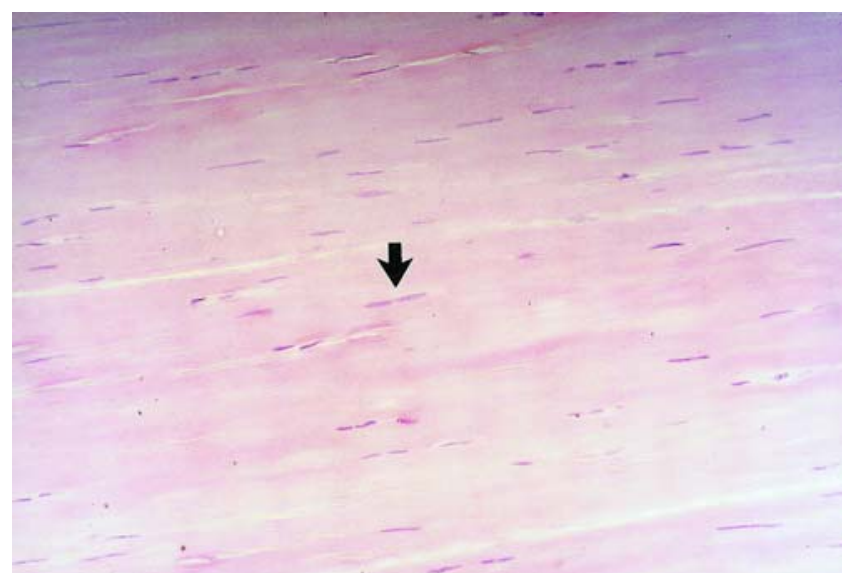

Fig. 1

Photomicrograph of a human patellar tendon after two weeks in tissue culture showing a longitudinal section of the superficial layers. Viable spindle-shaped nuclei of fibroblasts (arrow) indicate a normal cellular pattern (haematoxylin and eosin $\times 60$ ).

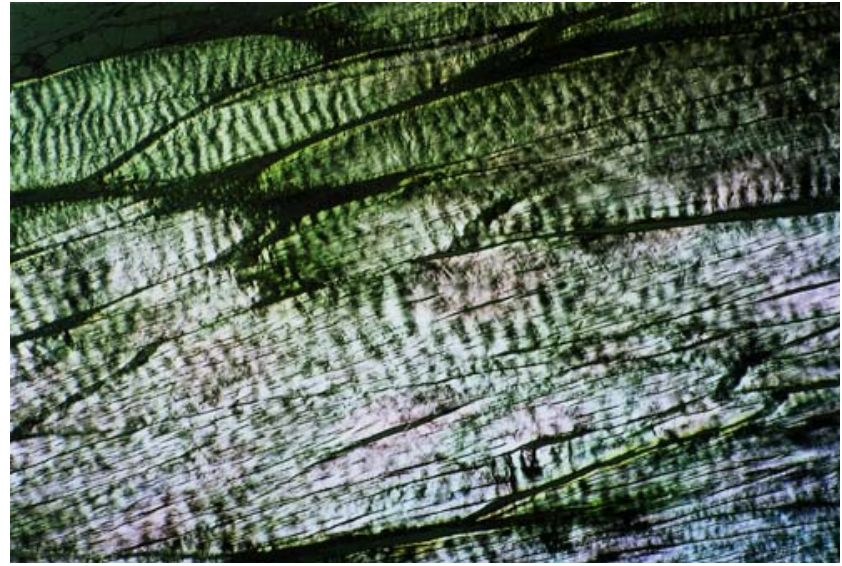

Fig. 3

Photomicrograph of a longitudinal section of a human patellar tendon after two weeks in tissue culture under polarised light. The crimp pattern of the collagen appears to be normal (haematoxylin and eosin $\times 23$ ).

The strain rate was $100 \mathrm{~mm} / \mathrm{min}$. The cyclic creep was given as the increase in length at $120 \mathrm{~N}$ between the first and tenth cycles relative to the resting length. After another 15 minutes of recovery the specimens were loaded until failure at a rate of strain of $10 \mathrm{~mm} / \mathrm{min}$.

Statistical analysis was performed using the Wilcoxon test for paired data.

\section{Results}

\section{Series 1}

Mechanical testing. There was no significant difference in the ultimate strength, linear stiffness and strain to maximum load between the control group and the cultured specimens (Table I). The failure modes are given in Table II. There was no significant difference between the groups.

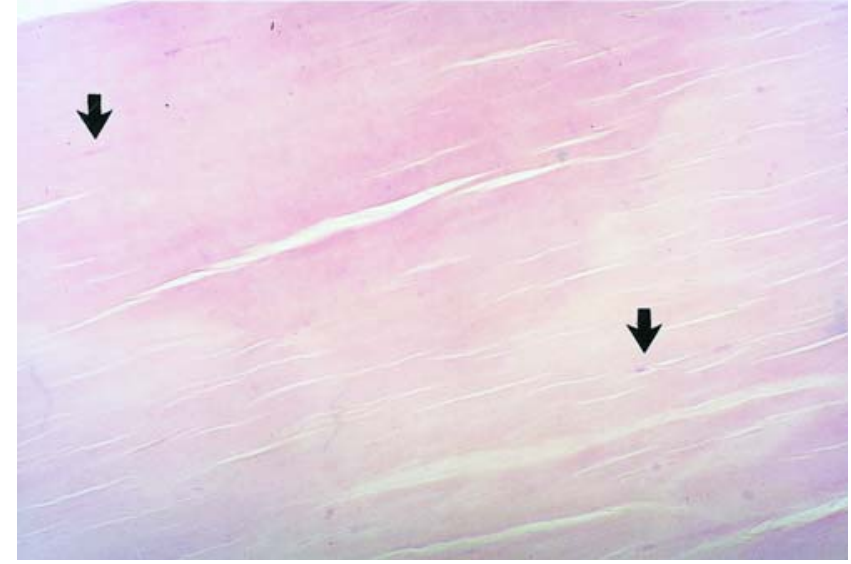

Fig. 2

Photomicrograph of a human patellar tendon after two weeks in tissue culture showing a longitudinal section of the central area. The central core of the graft has areas of acellularity. Only some nuclei of fibroblasts can be seen which are less easily stained (arrows) (haematoxylin and eosin $\times 60)$.

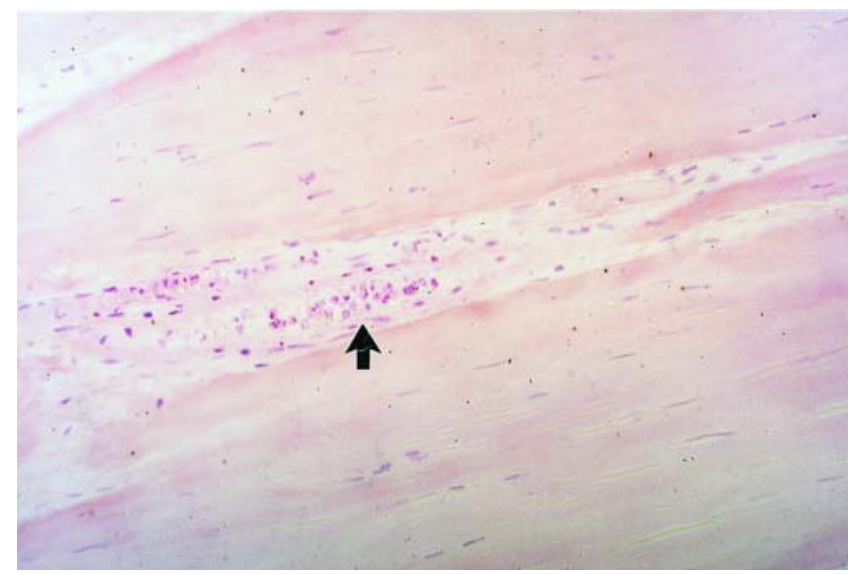

Fig. 4

Photomicrograph of the peritendineum area showing endothelial cells of blood vessels which are necrotic (arrow) and have lost their integrity forming clusters within the vessels. The surrounding tendon tissue appears to be normal with a regular distribution of viable fibroblasts (haematoxylin and eosin $\times 60$ ).

Histological findings. After two and four weeks the graft contained viable fibroblasts in the superficial layers (Fig. 1). The midportion showed a relative decrease in tissue cellularity with acellularity in scattered areas (Fig. 2). The structure of collagen including the crimp pattern appeared to be normal under polarised light (Fig. 3). The arrangement of the bundles was disturbed only in spotted areas in

Table II. Series 1. Mean failure modes of human BPTB grafts

\begin{tabular}{llll}
\hline & & Avascular \\
\cline { 3 - 4 } & Control group & 2 weeks & 4 weeks \\
\hline Tendon rupture & 7 & 2 & 1 \\
Tendon avulsion & 5 & 3 & 2 \\
Bone plug fracture & 8 & 4 & 5 \\
Complex failure & 2 & 2 & 3 \\
\hline
\end{tabular}


the mid-portion of some grafts. The endothelial cells of the blood vessels were necrotic and had lost their integrity forming clusters within the vessels (Fig. 4).

\section{Series 2}

Mechanical testing. There was no significant difference in the structural and material properties between the groups (Table III). Failure modes are given in Table IV. There was no significant difference between the groups.

Cyclic creep was $1.19 \pm 0.33 \%$ in the control group and $1.29 \pm 0.42 \%$ in cultured specimens. The difference was not statistically significant.

The final load-to-peak-load ratio (Fig. 5) after $15 \mathrm{~min}-$ utes was $70.9 \pm 5.2 \%$ in the control group and $65.1 \pm 5.6 \%$ in the avascular group. The difference was statistically significant $(\mathrm{p}<0.01)$.

\section{Discussion}

Animal studies have shown that BPTB grafts undergo changes in structure and a dramatic loss of tensile strength. In a canine model Butler et $\mathrm{al}^{6}$ found that the lowest maximum force (14\% of the opposite unaffected ACL) and the lowest stiffness ( $9 \%$ of the opposite unaffected ACL) occurred immediately after surgery. The tensile strength increased gradually to $28 \%$ of the control at 26 weeks. In monkeys ${ }^{11}$ the ultimate load was $16 \%$ and the stiffness $24 \%$ of the control ACL at seven weeks. Both increased at approximately the same rate up to 29 weeks after operation. In a goat model McPherson et $\mathrm{al}^{7}$ observed a maximum force to failure of $1 \%$ of the intact ACL immediately after surgery. Yoshiya et al, ${ }^{9}$ in a canine model, showed that the femur-patellar-tendon graft-tibia complex tested immediately after reconstruction failed at a load which was only $10 \%$ of that of the control patellar tendon. They stated that this was due to weakness at fixation sites. After three months, the value increased up to $20 \%$ of the control, and specimens failed in the graft substance. Ballock et $\mathrm{al}^{10}$ using a rabbit model showed that the stiffness was $15 \%$ and
Table III. Series 2. Structural and material properties (mean \pm SD) of human BPTB grafts. The cross-head speed was $10 \mathrm{~mm} / \mathrm{min}$

\begin{tabular}{lcc}
\hline & Control group & $\begin{array}{l}\text { Avascular group } \\
\text { (2 weeks) }\end{array}$ \\
\hline Ultimate load $(\mathrm{N})$ & $932.6 \pm 355.3$ & $951.2 \pm 399.5$ \\
Linear stiffness $(\mathrm{N} / \mathrm{mm})$ & $97.2 \pm 32.2$ & $106.1 \pm 33.4$ \\
Relative strain $(\%)$ & $28.9 \pm 9.6$ & $28.3 \pm 8.0$ \\
Ultimate stress $(\mathrm{MPa})$ & $29.1 \pm 10.3$ & $29.1 \pm 11.1$ \\
Elastic modulus $(\mathrm{MPa})$ & $148.6 \pm 63.6$ & $150.1 \pm 51.9$ \\
\hline
\end{tabular}

Table IV. Series 2. Mean failure modes of human BPTB grafts

\begin{tabular}{lcc}
\hline & Control group & $\begin{array}{l}\text { Avascular group } \\
\text { (2 weeks) }\end{array}$ \\
\hline Tendon rupture & 0 & 0 \\
Tendon avulsion & 2 & 3 \\
Bone plug fracture & 13 & 11 \\
Complex failure & 1 & 2 \\
\hline
\end{tabular}

the ultimate load $7 \%$ of the control immediately after surgery. Kasperczyk et al ${ }^{12}$ suggested that the decrease in tensile strength within the first weeks is caused by a deterioration of collagen tissue due to avascular necrosis. Examination of the experimental detail of these studies $^{6,7,9-11}$ shows that the authors had attached the femur and tibia to the testing machine. There were various methods of graft fixation and it is possible that the strengths reported related to fixation failure and not graft tissue failure. Therefore these data do not support the conclusion that the strength of a BPTB graft decreases dramatically immediately after surgery because of avascular necrosis of graft tissue.

In our study avascularity did not significantly alter the structural properties (maximum load, linear stiffness, deformation to maximum load) or material properties (maximum stress, elastic modulus) during maximal loading.

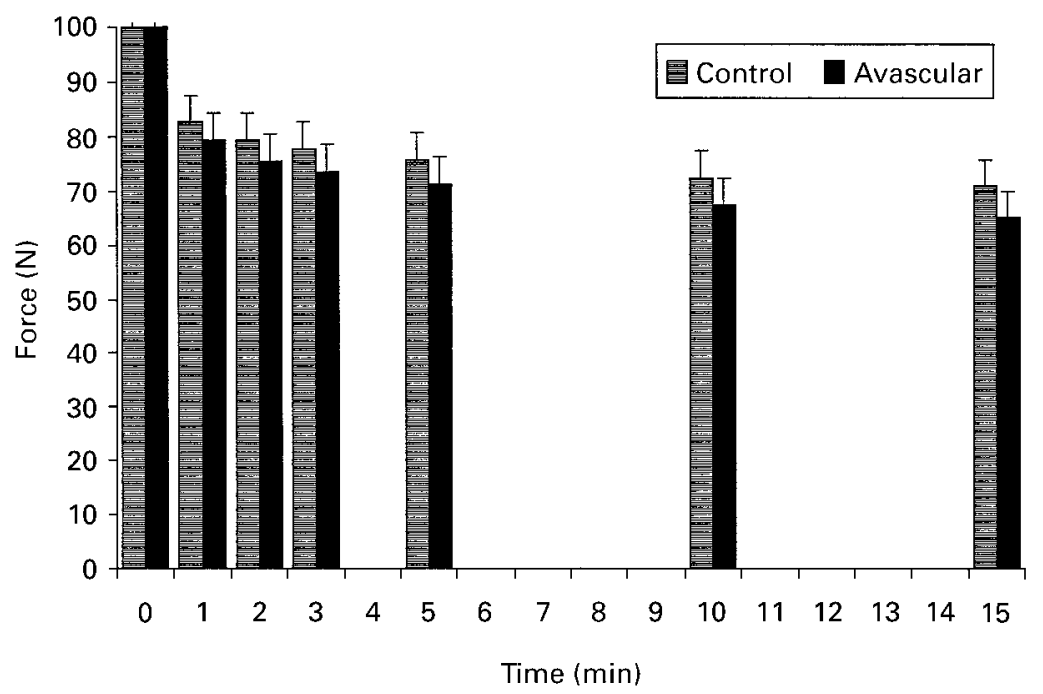

Fig. 5

Mean $( \pm \mathrm{SD})$ loss of tension because of viscoelastic relaxation which was significantly higher in avascular tendons $(\mathrm{p}<0.01)$. 
The failure loads of the specimens were relatively low compared with data given for young donors (mean age 26 and 28 years) in some studies. ${ }^{18,19}$ In these the mean maximum loads at failure were $2900 \mathrm{~N}^{18}$ and $3057 \mathrm{~N}{ }^{19}$ The cross-head speed was very high in both studies $(100 \%$ of the graft length/s). In addition, Noyes et $\mathrm{al}^{18}$ harvested grafts of $14 \mathrm{~mm}$ width which is not the standard surgical technique. In man the maximum width of a BPTB graft is usually $10 \mathrm{~mm}$.

The tensile strength and the linear stiffness of tendons and ligaments decrease with age. ${ }^{20,21}$ In addition, the failure loads of cadaver specimens depend on the activity level of the donors before death. ${ }^{22-24}$ In donors aged from 17 to 54 years Blevins et $\mathrm{al}^{25}$ observed a maximum load of $1693 \mathrm{~N}$ and a maximum stress of $35.9 \mathrm{MPa}$ which is not much higher than the results in our study although their donors were younger. Petermann et $\mathrm{al}^{26}$ reported an ultimate tensile strength of $1151 \mathrm{~N}$ (369 to 3008) in donors aged from 32 to 80 years. In donors with a mean age of 60 years Bechthold et $\mathrm{al}^{27}$ found an ultimate stress of 23.76 $\mathrm{MPa}$ which is lower than that in our study.

Woo et $\mathrm{al}^{21}$ investigated the structural properties of the femur-anterior-cruciate-ligament-tibia complex in younger (22 to 49 years) and older (60 to 97 years) donors. They found mean ultimate loads of $1954 \mathrm{~N}$ (younger donors) and $642 \mathrm{~N}$ (older donors) with a linear stiffness of $292 \mathrm{~N} / \mathrm{mm}$ and $179 \mathrm{~N} / \mathrm{mm}$, respectively. In our study the ultimate strength of the avascular BPTB grafts exceeded that of the femur-anterior-cruciate-ligament-tibia complex of the older donors of Woo et al. ${ }^{21}$

The design of our study using paired specimens reduces any bias related to the history of the donors and quality of the tendon. The model which we used isolated 'avascularity' in vitro and evaluated its impact on the structure and mechanical properties of the graft tissue. There may, however, be other environmental conditions which impair the mechanical performance of the graft in the knee after surgery.

The graft is not cyclically stressed as it is in the joint after operation, although ligaments become weaker when immobilised. $^{22-24}$ Therefore the lack of stress should not produce higher values of ultimate strength compared with the situation in vivo.

It is possible that there are aggressive factors similar to cytokine within synovial fluid after surgery. If these environmental factors have an impact on the morphology of the graft they should destroy graft tissue starting at the surface, as this is the area which is exposed to synovial fluid. Animal experiments $^{2-5,8}$ have shown, however, that the superficial layers of the graft remained intact with viable cells and a normal structural arrangement of the collagen fibres. Changes in histomorphology affected the central areas of the tissue with focal areas of cell death, hypocellularity and fragmentation of collagen. This is consistent with the histomorphology of avascular grafts in vitro. These experimental data may not support the theory of aggressive factors in synovial fluid, but are consistent with the view that avascularity is a significant environmental factor with respect to the histomorphology and biomechanics of the graft in the first weeks after surgery. The tendon tissue lacks a blood supply. Cells rely exclusively on diffusion for the supply of nutrients and oxygen. Nutrition of the cells in the central core of the graft may be insufficient due to the long diffusion distance. This would account for the pattern of histomorphological changes observed in animal studies.

There was a difference in the viscoelastic behaviour of the control and avascular groups. Avascular grafts had significant lower peak-load-to-load ratios after 15 minutes compared with the control group. Viscoelasticity may have an important role in the function of the graft, but its impact is not yet fully understood. The higher stress relaxation of avascular grafts may reduce the preload of the graft after surgery inducing more laxity of the joint. The concept of preconditioning of the graft $^{28,29}$ is based on this theory. With an increased stress relaxation of avascular grafts preconditioning may be even more important to maintain the preload of the graft. On the other hand stress relaxation may protect collagen tissue during avascularity by reducing the load induced by rehabilitation.

We conclude that avascularity does not significantly affect ultimate failure loads or stiffness of BPTB grafts. Slight changes in viscoelasticity are induced, but the significance of the increased stress relaxation is not yet fully understood.

No benefits in any form have been received or will be received from a commercial party related directly or indirectly to the subject of this article.

\section{References}

1. Campbell JD. The evolution and current treatment trends with anterior cruciate, posterior cruciate, and medial collateral ligament injuries. Am J Knee Surg 1998;11:128-35.

2. Alm A, Strömberg B. Transposed medial third of patellar ligament in reconstruction of the anterior cruciate ligament: a surgical and morphological study in dogs. Acta Chir Scand Suppl 1974;445:37-49.

3. Chiroff RT. Experimental replacement of the anterior cruciate ligament: a histological and macroradiographic study. J Bone Joint Surg [Am] 1975;57-A:1124-7.

4. Clancy WG, Narechania RG, Rosenberg TD, et al. Anterior and posterior cruciate ligament reconstruction in Rhesus monkeys. J Bone Joint Surg [Am] 1981;63-A:1270-84.

5. Arnoczky SP, Tarvin GB, Marshall JL. Anterior cruciate ligament replacement using patellar tendon: an evaluation of graft revascularisation in the dog. J Bone Joint Surg [Am] 1982;64-A:217-24.

6. Butler DL, Hulse DA, Kay MD, et al. Biomechanics of cranial cruciate ligament reconstruction in the dog: II. Mechanical properties. Vet Surg 1983;12:113-8.

7. McPherson GK, Mendenhall HV, Gibbons DF, et al. Experimental, mechanical and histologic evaluation of the Kennedy ligament augmentation device. Clin Orthop 1985;196:186-95.

8. Amiel D, Kleiner JB, Roux RD, Harwood FL, Akeson WH. The phenomenon of 'ligamentization': anterior cruciate ligament reconstruction with autogenous patellar tendon. JOrthop Res 1986;4:162-72.

9. Yoshiya S, Andrish JT, Manley MT, Kurosaka M. Augmentation of anterior cruciate ligament reconstruction in dogs with prostheses of different stiffnesses. J Orthop Res 1986;14:475-85.

10. Ballock RT, Woo SL-Y, Lyon RM, Hollis JM, Akeson WH. Use of patellar tendon autograft for anterior cruciate ligament reconstruction in the rabbit: a long term histological and biomechanical study. J Orthop Res 1989;4:474-85. 
11. Butler DL, Grood ES, Noyes FR, et al. Mechanical properties of primate vascularised versus non-vascularised patellar tendon grafts: changes over time. J Orthop Res 1989;7:68-79.

12. Kasperczyk W, Bosch U, Oestern HJ, Tscherne H. Die Biomechanik des heilenden, autologen Patellarsehnentransplantates und die Bedeutung einer Augmentation: Eine tierexperimentelle Studie zum Ersatz des hinteren Kreuzbandes. In: Claes L, ed. Die wissenschaftlicchen Grundlagen des Bandersatzes. Berlin, etc: Springer Verlag, 1994:234:98-135.

13. Alm A, Gillquist J, Strömberg B. The medial third of the patellar ligament in reconstruction of the anterior cruciate ligament: a clinical and histologic study by means of arthroscopy or arthrotomy. Acta Chir Scand 1974;445:5-14.

14. Abe S, Kurosaka M, Iguchi T, Yoshiya S, Hirohata K. Light and electron microscopic study of remodelling and maturation process in autogenous graft for anterior cruciate ligament reconstruction. Arthroscopy 1993;9:394-405.

15. Rougraff B, Shelbourne KD, Gerth PK, Warner J. Arthroscopic and histologic analysis of human patellar tendon autografts used for anterior cruciate ligament reconstruction. Am J Sports Med 1993;21:277-84.

16. Amiel D, Kuiper S. Experimental studies on anterior cruciate ligament grafts: histology and biochemistry. In: Daniel DM, Akeson WH, O'Connor JJ, eds. Knee ligaments: structure, function, injury and repair. New York: Raven Press, 1990:379-88.

17. Shelbourne KD, Nitz P. Accelerated rehabilitation after anterior cruciate ligament reconstruction. Am J Sports Med 1990;18:292-9.

18. Noyes FR, Butler DL, Grood ES, Zernicke RF, Hefzy MS. Biomechanical analysis of human ligament grafts used in knee-ligament repairs and reconstructions. J Bone Joint Surg [Am] 1984;66-A:34452

19. Cooper DE, Deng XH, Burstein AL, Warren RF. The strength of the central third patellar tendon graft: a biomechanical study. Am J Sports Med 1993;21:818-24.
20. Noyes FR, Grood ES. The strength of the anterior cruciate ligament in humans and rhesus monkeys: age-related and species-related changes. J Bone Joint Surg [Am] 1976;58-A:1074-82.

21. Woo SL, Hollis JM, Adams DJ, Lyon RM, Takai S. Tensile properties of the human femur-anterior cruciate liagment-tibia complex: the effects of specimen age and orientation. Am J Sports Med 1991; 19:217-25.

22. Noyes FR. Functional properties of knee ligaments and alterations induced by immobilization: a correlative biomechanical and histological study in primates. Clin Orthop 1977;123:210-42.

23. Woo SL, Gomez MA, Woo YK, Akeson WH. Mechanical properties of tendons and ligaments. II: the relationships of immobilisation and exercise on tissue remodelling. Biorheology 1982;19:397-408.

24. Woo SL-Y, Gomez MA, Sites TJ, et al. The biomechanical and morphological changes in the medial collateral ligament of the rabbit after immobilisation and remobilisation. J Bone Joint Surg [Am] 1987;69-A:1200-11.

25. Blevins FT, Hecker AT, Bigler GT, Boland AL, Hayes WC. The effects of donor age and strain rate on the biomechanical properties of bone-patellar bone-bone allografts. Am J Sports Med 1994;22:328-33.

26. Petermann J, Möhling K, Niess C, Gotzen L, Garrel T. Measurement of tensile properties of the central third of the human patellar tendon as affected by age and immobilisation. Arthroskopie 1998;11:56-60.

27. Bechthold JE, Eastlund DT, Butts MK, Lagerborg DF, Kyle RF. The effects of freeze-drying and ethylene oxid sterilization on the mechanical properties of human patellar tendon. Am J Sports Med 1994;22:562-6.

28. Graf BK, Vanderby R Jr, Ulm MJ, Rogalski RP, Thielke RJ. Effect of preconditioning on the viscoelastic response of primate patellar tendon. Arthroscopy 1994;10:90-6.

29. Schatzmann L, Brunner P, Stäubli HU. Effect of cyclic preconditioning on the tensile properties of human quadriceps tendons and patellar ligaments. Knee Surg Sports Traumatol Arthrosc 1998;6Suppl 1:56-61. 